sible breeding areas in the northern Great Plains. At least in the spring of 1964, dyed Ring-bills were seen following plows in fields in western Nebraska about two weeks after being released in Colorado. Similar sightings were reported in southeastern Wyoming in the spring of 1965 . The lack of sightings reported in South Dakota, northern Wyoming and southeastern Montana is probably influenced by the fact that there are relatively few observers in those areas, but it may indicate that few of our marked gulls stopped in those areas.
As might be expected, most of our observations in both spring and fall have been in north-central Colorado (Table 1), where undoubtedly more people were aware of our studies, and where the gulls had not yet lost much of the dye either by moulting or fading. Most dyed gulls retained fairly good coloring for three to four months, although we had a few recognizable as long as six months. Two gulls with neck tags were observed in normal white plumage in the fall of 1963 , almost one year following initial banding.

\title{
UNUSUAL ACCIDENT INVOLVING A CALIFORNIA GULL
}

\author{
by Spencer G. Sealy, Battleford
}

Colonial birds are confronted with many dangers. A predator may drastically reduce the number of young gulls in a colony, rising water levels may flood a "gull island", or young birds may be killed in falling off a ledge, or become permanently wedged in a crevice. One or more of these dangers are usually present as factors limiting the population of each colony. This note describes an unusual type of accident involving an adult California Gull (Larus californicus) on "Bird Island" in Lake Newell, 20 miles south of Brooks, Alberta. This island, about 500 yards long and 100 yards wide, lies in an east-west direction, with its south-facing side gradually sloping into the water, while its north-facing side, which drops abruptly, is undergoing water erosion.

While banding California Gulls and Doubl e-crested Cormorants (Phalacrocorax auritus) on June 19, 1965, C. A. Gordon, J. P. Ryder, J. A. Wolford and I discovered a gull partially covered by earth which had fallen from the eroded north-facing side of this island (see photograph). Only the bird's head, neck and one wing protruded, rendering it completely helpless. The bird was subse- quently removed, found to be in a very weak state, and released on the island. It is not known whether it survived. Later it was found that many young gulls sought refuge at the base of this eroded bank, thus rendering them vulnerable to a similar accident; however, no juvenile mortalities resulting from this type of accident were discovered. It is possible that falling earth may have completely covered some of the young, making them impossible to be seen without excavation.

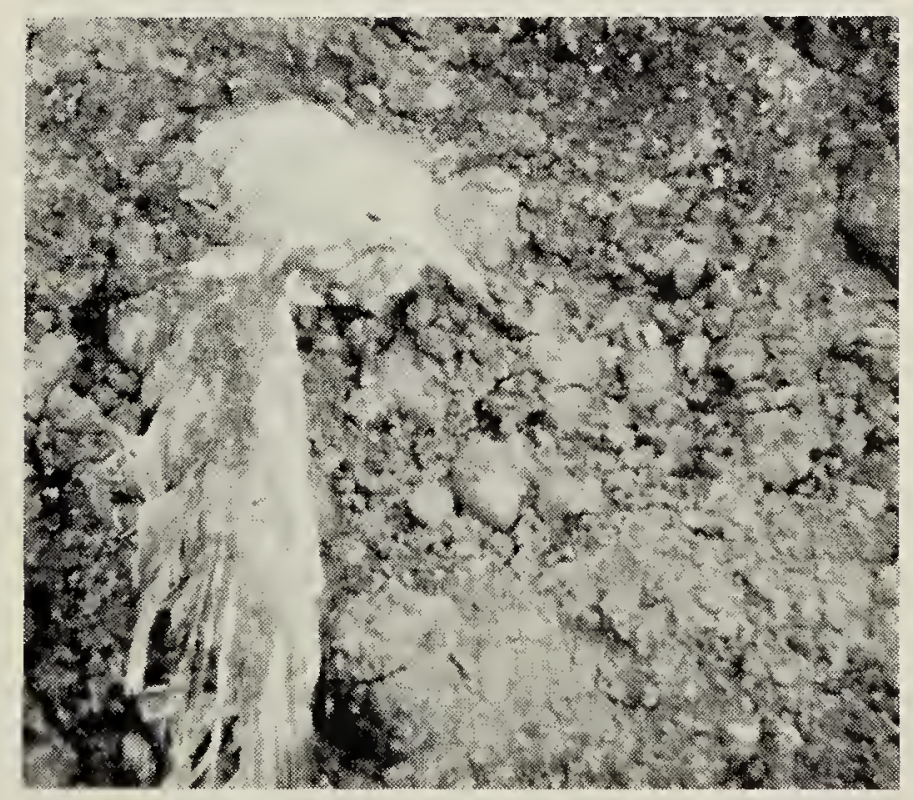

Photo by S. G. Sealy 